\title{
Efficacy of a self-management plan in exacerbations for patients with advanced COPD
}

\author{
This article was published in the following Dove Press journal: \\ International Journal of COPD \\ 17 August 2016 \\ Number of times this article has been viewed
}

\author{
Juan Miguel Sánchez- \\ Nieto ${ }^{1,2}$ \\ Rubén Andújar-Espinosa ${ }^{3}$ \\ Roberto Bernabeu-Mora ${ }^{1,2}$ \\ Chunshao $\mathrm{Hu}^{\prime}$ \\ Beatriz Gálvez-Martínez' \\ Andrés Carrillo-Alcaraz' \\ Carlos Federico Álvarez- \\ Miranda ${ }^{3}$ \\ Olga Meca-Birlanga' \\ Eva Abad-Corpa ${ }^{4}$ \\ 'Division of Pneumology, Hospital \\ Morales Meseguer, ${ }^{2}$ University of \\ Murcia, ${ }^{3}$ Division of Pneumology, \\ Hospital Arrixaca, Murcia, \\ ${ }^{4}$ Department of Professional \\ Development Unit, Murcia, Spain
}

Correspondence: Roberto Bernabeu-Mora Division of Pneumology, Hospital Morales Meseguer, Avda Marqués de los Vélez s/n, 30008 Murcia, Spain

Tel +34968360900

Fax +34968360994

Email rbernabeumora@hotmail.com
Background: Self-management interventions improve different outcome variables in various chronic diseases. Their role in COPD has not been clearly established. We assessed the efficacy of an intervention called the self-management program on the need for hospital care due to disease exacerbation in patients with advanced COPD.

Methods: Multicenter, randomized study in two hospitals with follow-up of 1 year. All the patients had severe or very severe COPD, and had gone to either an accident and emergency (A\&E) department or had been admitted to a hospital at least once in the previous year due to exacerbation of COPD. The intervention consisted of a group education session on the main characteristics of the disease, an individual training session on inhalation techniques, at the start and during the 3rd month, and a written action plan containing instructions for physical activity and treatment for stable phases and exacerbations. We determined the combined number of COPD-related hospitalizations and emergency visits per patient per year. Secondary endpoints were number of patients with visits to $A \& E$ and the number of patients hospitalized because of exacerbations, use of antibiotics and corticosteroids, length of hospital stay, and all-cause mortality.

Results: After 1 year, the rate of COPD exacerbations with visits to A\&E or hospitalization had decreased from 1.37 to $0.89(P=0.04)$ and the number of exacerbations dropped from 52 to 42 in the group of patients who received the intervention. The numbers of patients hospitalized, at $19(40.4 \%)$ versus $20(52.6 \%)(P=0.26)$, and those who went to $\mathrm{A} \& \mathrm{E}$, at $9(19.1 \%)$ versus $14(36.8 \%)(P=0.06)$, due to exacerbation of COPD were also lower in this group. Intake of antibiotics was higher in the intervention group, whereas use of glucocorticoids was slightly lower, though there were no significant differences $(P=0.30)$. There were also no differences between groups in the length of hospital stay $(P=0.154)$ or overall mortality $(P=0.191)$.

Conclusion: The implementation of a self-management program for patients with advanced COPD reduced exacerbations that required hospital care.

Keywords: self-management, COPD, severe exacerbations

\section{Introduction}

COPD is a large and growing public health problem; it is now the most costly respiratory disease in Europe. ${ }^{1}$ COPD is an irreversible and debilitating disease that progresses through different stages and has a huge impact on patients' functional performance and quality of life. ${ }^{2}$ It is also characterized by episodes of acute exacerbation that are a particular problem in the control of the disease because of the negative impact on quality of life, ${ }^{3,4}$ prognosis, and costs. ${ }^{5,6}$ In addition to the severity of COPD, there are other concomitant factors, such as comorbidities and unmet social/health needs due to poor self-management of the disease, which can affect rates of hospital admissions and use of health care resources for these patients. ${ }^{7}$ In this context, different 
"nonpharmacological interventions" involving self-management are being developed, based on chronic care models ${ }^{8}$ with the aim of improving prognosis and reducing the use of resources. ${ }^{9}$ Self-management in COPD patients was defined as active involvement in the management of their disease, based on sufficient coping behavior to achieve optimal compliance and be able to take action against symptoms of exacerbation. ${ }^{10}$ The term "self-management plan" can apply to any formal education program aimed at teaching the skills needed to follow specific medical regimens, guiding the change toward healthy attitudes and providing support to patients to help them manage their disease. ${ }^{11}$ To date, there are few data available regarding which methods are the most effective in improving self-management, especially in reducing the number of exacerbations. One potentially effective method might be to help patients recognize and anticipate the initial symptoms of an exacerbation by way of an "action plan". There is only a relatively moderate amount of evidence on the efficacy of self-management programs in COPD. Such programs have mainly been directed at other chronic conditions, such as heart failure, diabetes, and asthma, where, in fact, they have been successful in achieving significant improvements in many processes, although few studies have demonstrated significantly reduced costs. ${ }^{12,13}$ A Cochrane systematic review including three controlled trials evaluated written action plans only as a single intervention component, with a relatively small number of patients and methodological limitations, showing no beneficial effects on clinical outcomes or resource use, although they did improve selfmanagement strategies against exacerbations. ${ }^{14}$ In contrast, another systematic review on the effectiveness of the chronic care model in COPD found that patients who received interventions with two or more components had lower health care resource use compared to controls. ${ }^{15}$ In the most recent review by Zwerink et al, ${ }^{16}$ self-management interventions in patients with COPD were associated with better quality of life, fewer hospital admissions and improved symptoms; however, the heterogeneity of the interventions applied and the outcome measures make it difficult to provide recommendations on which components were most effective. Data on the role of self-management plans for COPD in improving the use of health care resources or patient health remain insufficient, and further research is needed in this area. ${ }^{17}$

This study evaluates the efficacy of a self-management intervention added to usual care in a randomized, controlled study. Our hypothesis is that a multiple component intervention called a COPD self-management program (SMP-COPD), led by a multidisciplinary team, could significantly reduce the use of health care resources and, in particular, the number of exacerbations requiring hospital care.

\section{Methods}

\section{Patient selection}

Patients were recruited between February 2012 and March 2013 from two hospitals (Hospital Morales Meseguer for the health area VI and Hospital Arrixaca for the health area I) in the Autonomous Region of Murcia (Spain). Each hospital served mainly an urban area with a population of 250,000 people; they had accident and emergency (A\&E) units and accepted general and specialized admissions. Patients were recruited from each hospital's database if they had been treated in the A\&E or had been hospitalized for an exacerbation of COPD at least once during the year prior to inclusion in the study. Patients were called to participate in the study if at least 3 months had elapsed since the episode of hospital care. Patients were included if they met the following criteria: 1) clinical stability (at least in the 3 months prior to randomization, with no change in medication or usual symptoms); 2) active smoker or prior history of smoking of at least 10 pack-years; 3 ) post-bronchodilator forced expiratory volume in 1 second/ forced vital capacity ratio $<70 \%$; 4) normal cognitive status (assessed by the intersecting pentagons test ${ }^{18}$ ) to read and understand written texts, and receive training in inhalation techniques or self-care education sessions; 5) physical status that allows for regular walking or exercise; 6) no diagnoses of asthma, advanced heart failure, unstable ischemic heart disease, terminal disease, dementia, or uncontrolled psychiatric disorders; 7) ability to read texts; 8) no participation in any pulmonary rehabilitation program in the previous year.

The study was approved by the institutional review boards of the hospitals "Comité Ético de Investigación Clínica del Hospital General Universitario José María Morales Meseguer" and "Comité Ético de Investigación Clínica del Hospital Arrixaca". Written informed consent was obtained from all patients.

\section{Study design}

Controlled, randomized, parallel-group, single-blind study with follow-up of 1 year. After consenting to take part in the study, simple randomization was carried out separately at each site by means of a list of computer-generated random numbers, assigning the patients to two groups. The intervention group (IG) received the SMP-COPD program on an individualized basis. The comparison group, or control group (CG), received routine care and attended routine visits. Because double-blinding was not possible, an independent evaluator, who did not know the patients' group assignments, was 
responsible for evaluating the outcome variables. CG patients and IG patients continued to see their respective specialists and primary care physicians, and had access to health care or public health programs and home respiratory therapies. Each patient randomized to the IG received the SMP-COPD, which consisted of a group education session on the main characteristics of the disease, an individual training session on inhalation techniques according to the devices indicated for each patient, and an action plan with written material consisting of color-coded sheets with treatment instructions for the stable periods, including recommendations for physical exercise (green) and exacerbations (orange). In addition to the visits at the start and the end of the study (the same for both groups), the IG had two extra visits with a respiratory nurse (at 1 and 3 months into the study), primarily to check on the correct use of the treatment instructions sheets and inhalation techniques. Training in inhalation techniques was a systematic, protocol-based process for training all patients in the IG, individually teaching correct administration technique for each prescribed inhaler, with particular emphasis on both avoiding critical errors and adherence.

The SMP-COPD was taught and supervised by professionals previously trained in the intervention's features: six nurses, two physiotherapists, and six medical specialists in respiratory medicine.

\section{Self-management program}

The material in the group education session was designed specifically for the program and consisted of a PowerPoint presentation with 20 slides on the main characteristics of the disease, symptoms of exacerbation, and inhaled medicines. At the end, there was a chance for questions and a physiotherapist demonstrated how to do a series of basic physical exercises. Each session was delivered by a previously trained nurse to a group of six to eight patients.

The action plan consisted of a folder containing written material with four kinds of sheets. Sheets with instructions on treatment and physical exercises for stable periods (green), treatment sheets for exacerbations (orange), and a red sheet with instructions to follow in the case of their condition becoming serious or an emergency. The fourth sheet contained instructions for inhalation techniques. The exacerbation sheets explained the symptoms of bronchial infection for which they should start antibiotics and that if the symptoms did not improve within 48 hours or they developed dyspnea, they should start a course of oral glucocorticoids for 6 days. There were also instruction sheets on inhalation techniques, which explained the correct use and main features of the type of inhaler indicated for each patient. To ensure proper understanding of the texts included in the sheets, their readability was assessed by the computer program Microsoft Word 2000 (1983-1999 Microsoft Corporation, Redmon, WA, USA).

\section{Measures}

\section{Follow-up and evaluation of variables}

All the study visits were conducted at one of the two participating hospitals (A or B). Sociodemographic variables were collected at the baseline visit and included: respiratory symptoms; medical history and physical examination; body mass index; smoking status and accumulated intake; spirometry parameters; dyspnea (modified Medical Research Council dyspnea scale); ${ }^{19}$ quality of life ${ }^{20}$ (COPD assessment test); severity of COPD according to the Global Initiative for Chronic Obstructive Lung Disease, ${ }^{21}$ comorbidity index;22 respiratory medicines; and a social-risk questionnaire. ${ }^{23}$ The latter is a hetero-administered questionnaire validated for the detection of social risk that explores the five areas of family, financial and housing situations, social relationships, and social support networks (a score $>15$ indicates social problems). Information was collected on the use of antibiotics and glucocorticoids, number of visits to a hospital, A\&Es, and admissions, including length of hospital stay for COPD exacerbation during the follow-up period. The primary outcome was the combined number of hospital admissions and A\&E visits for COPD during the 12-month follow-up period. Secondary outcomes included individual components of the primary outcome: hospitalizations and $A \& E$ visits for COPD exacerbations, lengths of stay, number of patients who received antibiotic or glucocorticoid treatment and all-cause mortality. Exacerbation of COPD was defined as a sustained worsening of the patient's condition from a stable state, with acute onset and beyond normal day-to-day variations, which requires treatment or additional care. ${ }^{24}$ Hospitalization due to COPD was defined as any admission where a hospital bed was used, in any unit and of any duration, and for which the diagnosis was listed as COPD aggravation or exacerbation. A visit to the hospital A\&E for exacerbation of COPD was defined as remaining in this area for over 8 hours and receiving treatment with bronchodilators, parenteral corticosteroids, and oxygen.

\section{Statistical analysis}

Sample size: accepting an alpha risk of 0.05 and a beta risk of 0.2 in a two-tailed test, 89 subjects were needed in total to detect an absolute difference of $30 \%$ in the reduction of exacerbations with hospital care (visit to A\&E or admission), with $70 \%$ of the patients expected to be treated in hospital for an exacerbation during the year of follow-up. A loss rate of $7 \%$ of patients was estimated. 
The analysis of the results was performed using the intention-to-treat principle, where each patient was analyzed in the group to which they were initially randomized. Patients lost to follow-up (inability to follow up due to a change of address) were evaluated until the time of the last contact with them by the research staff.

The results were expressed as mean \pm standard deviation for quantitative variables and as percentages for qualitative variables, and $95 \%$ confidence intervals were calculated for the outcome variables. The comparison between qualitative variables was performed using Pearson's chi-squared test or Fisher's exact test. The comparison between quantitative and qualitative variables was performed using Student's $t$-test or the Mann-Whitney $U$-test, depending on whether the qualitative variable was distributed normally or not. The comparison between quantitative variables was performed with a test to compare the means for paired data. McNemar's test was used to compare related qualitative data in addition to the test for comparison of related means. The time-related outcome variables were compared using Kaplan-Meier curves with the logrank test. All comparisons were made using a two-tailed test. For the analysis, the statistical package SPSS ${ }^{\circledR}$ version 15.0 (IBM SPSS., Chicago, IL, USA) for Windows ${ }^{\circledR}$ was used.

\section{Results}

\section{Study patients}

The study patients were followed up from April 2013 to January 2014. In all, 250 patients from two health regions were recruited. Number excluded: 149 (59.6\%); 33 patients (22.1\%) due to severe comorbidities (12 cancers, 13 advanced heart failure, six unstable coronary heart disease, and two renal failure); 37 patients (14.8\%) who, in the investigator's opinion, were too physically disabled at the time of first visit to benefit from the exercise program in the written action plan and the group educational session; 23 patients $(9.2 \%)$ in whom the diagnosis of COPD was not confirmed; 16 patients (6.4\%) due to cognitive impairment ("pentagons test"); 15 patients (6\%) who refused to take part; and finally, 12 patients (4.8\%) due to psychosocial problems. Of the 101 patients enrolled, five did not attend the randomization visit. In all, 96 patients (38.4\%) were randomized, 45 of whom (46.8\%) were included in the CG and 51 (53.1\%) in the IG. In the end, 85 patients (88.5\%) completed the study: 38 patients in the CG (18 [47.4\%] in area VI and 20 [52.6\%] in area I); and 47 patients in the IG (25 [53.2\%] in area VI and $22[46.8 \%]$ in area I; $P=0.593)$. In the $\mathrm{CG}$, seven patients were lost to follow-up (one protocol violation and six dropouts), and in the IG, four were lost (one protocol violation and three dropouts). The patients recruited for the study are shown in Figure 1.

\section{Patient characteristics}

In all, 78 men $(91.76 \%)$ were included and seven women (8.24\%). Mean age: $C G=67.6 \pm 6.9$ years; and $\mathrm{IG}=68.4 \pm 7.3$ years. Forty-two patients $(43.7 \%)$ were recruited from hospital A and the other 54 (56.2\%) from hospital B. There were no significant differences between

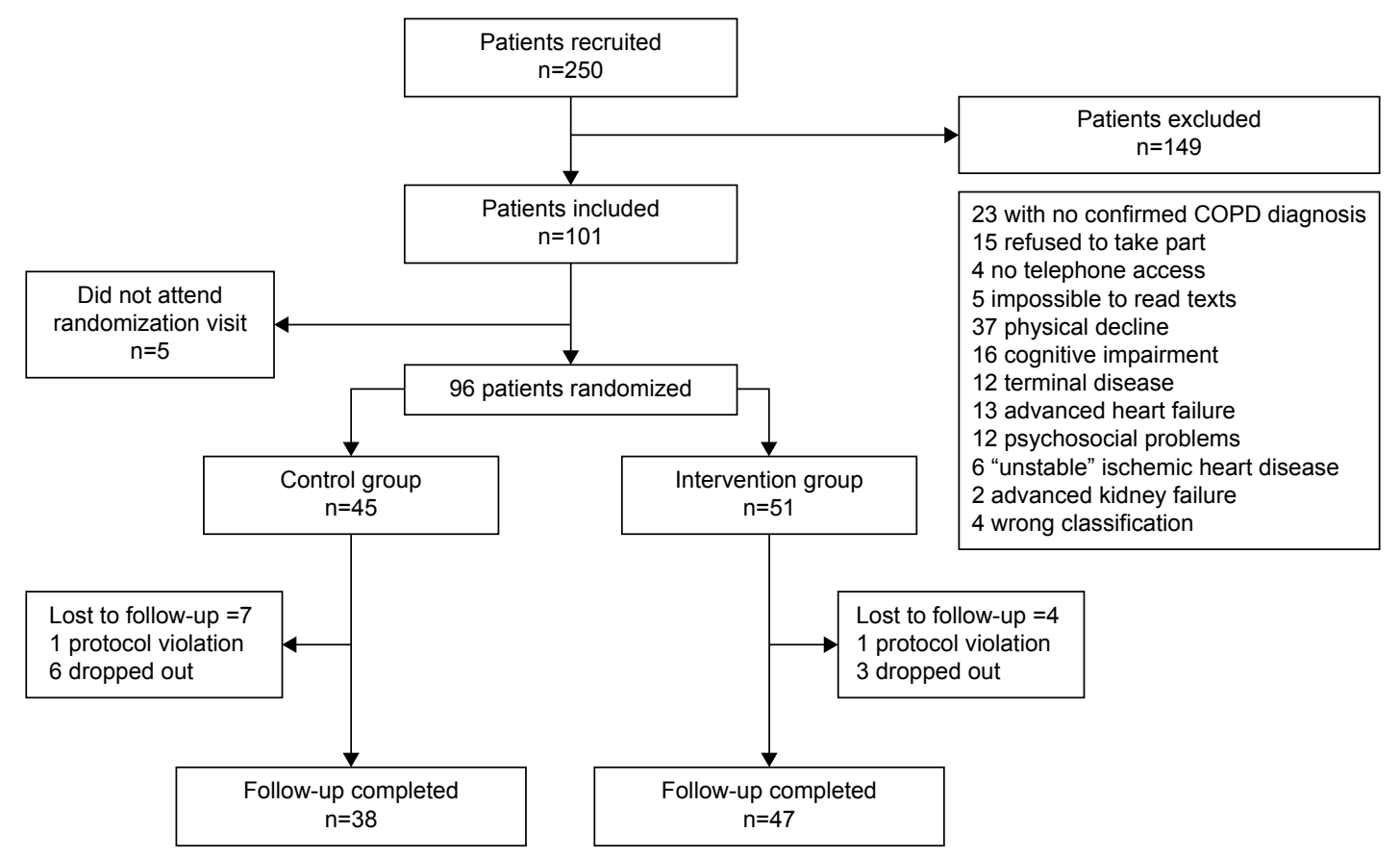

Figure I Patients included for the study. 
Table I Baseline characteristics of the patients aleatorized and analyzed at the start of the study

\begin{tabular}{|c|c|c|c|c|c|c|}
\hline \multirow{3}{*}{$\begin{array}{l}\text { Characteristics of the } \\
\text { patients }\end{array}$} & \multicolumn{3}{|l|}{ Aleatorization } & \multicolumn{3}{|l|}{ Analyzed } \\
\hline & \multirow{2}{*}{$\begin{array}{l}\text { Control } \\
\mathrm{N}: 45\end{array}$} & \multirow{2}{*}{$\begin{array}{l}\text { Intervention } \\
\mathrm{N}: \mathbf{5 I}\end{array}$} & \multirow[t]{2}{*}{$P$-value } & \multirow{2}{*}{$\begin{array}{l}\text { Control } \\
\mathrm{N}: 38\end{array}$} & \multirow{2}{*}{$\begin{array}{l}\text { Intervention } \\
\mathrm{N}: 47\end{array}$} & \multirow[t]{2}{*}{$P$-value } \\
\hline & & & & & & \\
\hline Male/female & 40 (88.9\%)/5 (II.1\%) & 47 (92.2\%)/4 (7.8\%) & 0.730 & $34(89.5 \%) / 4(10.5 \%)$ & $44(93.6 \%) / 3(6.4 \%)$ & 0.695 \\
\hline Age & $67.1 \pm 6.8$ & $68.2 \pm 7.2$ & 0.437 & $67.7 \pm 6.9$ & $68.5 \pm 7.3$ & 0.618 \\
\hline Body mass index & $26.4 \pm 8.9$ & $25.6 \pm 10.1$ & 0.698 & $25.6 \pm 9.7$ & $25.7 \pm 10.5$ & 0.674 \\
\hline Social risk scale & $5.1 \pm 3.1$ & $5.1 \pm 2.8$ & 0.950 & $5.3 \pm 3.2$ & $5.1 \pm 2.9$ & 0.864 \\
\hline Comorbidity index & $\mathrm{I}(\mathrm{I} .2)$ & $\mathrm{I}(1.2)$ & 0.552 & $\mathrm{I}(\mathrm{I} .2)$ & $\mathrm{I}(\mathrm{I} .2)$ & 0.849 \\
\hline Active smoker & $16(35.6 \%)$ & 19 (37.3\%) & 0.562 & 14 (36.8\%) & 19 (40.4\%) & 0.520 \\
\hline Pack-years index & $52.5 \pm 26.2$ & $56.9 \pm 44.3$ & 0.565 & $53.1 \pm 28.3$ & $57.7 \pm 46.1$ & 0.586 \\
\hline Quality of life (CAT) & $|4| \pm 6.4$. & $17.8 \pm 6.4$ & 0.334 & $14.6 \pm 6.8$ & $12.9 \pm 6.7$ & 0.286 \\
\hline Dyspnea (mMRC) & $2(2.3)$ & $2(1.3)$ & 0.348 & $2(2.3)$ & $2(1.3)$ & 0.261 \\
\hline $\mathrm{FEV}_{1}(\%)$ & $44.3 \pm 11.9$ & $47.3 \pm 14.4$ & 0.270 & $45.2 \pm 12.7$ & $47.2 \pm 14.7$ & 0.519 \\
\hline Severe COPD & II (24.4\%) & I 4 (27.4\%) & 0.918 & $9(20 \%)$ & 14 (27.4\%) & 0.700 \\
\hline Very severe COPD & $30(66.7 \%)$ & $34(66.7 \%)$ & 0.829 & $25(65.8 \%)$ & 30 (63.8\%) & 0.968 \\
\hline Hospitalization due to COPD & $33(73.3 \%)$ & 35 (68.6\%) & 0.613 & $29(76.3 \%)$ & $31(66 \%)$ & 0.297 \\
\hline No hospitalization & $\mathrm{I}(\mathrm{I} .2)$ & $\mathrm{I}(0.1)$ & 0.712 & $\mathrm{I}(\mathrm{I} .2)$ & $\mathrm{I}(0.1)$ & 0.261 \\
\hline Emergency visits due to COPD & $29(64.4 \%)$ & $50(58.8 \%)$ & 0.572 & 22 (57.9\%) & $27(57.4 \%)$ & 0.967 \\
\hline No emergency room visits & $\mathrm{I}(0.2)$ & $\mathrm{I}(0.2)$ & 0.308 & $\mathrm{I}(0.2)$ & $\mathrm{I}(0.2)$ & 0.435 \\
\hline
\end{tabular}

Note: Values given as number (\%), mean \pm SD or median (quartiles I and 3).

Abbreviations: CAT, COPD Assessment Test; FEV , forced expiratory volume in I second; mMRC, modified Medical Research Council; N, number; SD, standard deviation.

the two groups at baseline in terms of age or sex, or on the social-risk scale. There were also no significant differences in other clinical characteristics, such as the Charlson index, body mass index or dyspnea (modified Medical Research Council) scale. Quality of life (COPD assessment test) showed a mean score of $15.2 \pm 5.9$ in the $C G$ and $13.6 \pm 6.9$ in the $\mathrm{IG}(P=0.286)$. In the $C G$, there were 14 cases $(34.9 \%)$ of active smokers compared with 16 cases $(38.1 \%)$ in the IG $(P=0.546)$, and accumulated intake was comparable between the two groups $(P=0.586)$. Functional parameters were also very similar in both groups, and almost all the patients had advanced COPD, classified as very serious in $71 \%$ of CG patients and $61.7 \%$ of IG patients $(P=0.151)$. Only four patients $(10.5 \%)$ from the CG and three patients (6.3\%) from the IG had mild or moderate COPD (2007 Global Initiative for Chronic Obstructive Lung Disease classification. www.goldcopd.org). ${ }^{21}$ Table 1 shows the baseline characteristics of the two groups.

\section{Outcome variables}

The combined primary outcome variable, the rate of COPD exacerbations with visit to A\&E or hospitalization, fell from 1.37 to $0.89(P=0.04)$ in the IG. The number of exacerbations in the IG also dropped from 52 to 42 . The numbers of patients hospitalized, at $19(40.4 \%)$ versus $20(52.6 \%)(P=0.26)$, and those who went to $\mathrm{A} \& \mathrm{E}$, at $9(19.1 \%)$ versus $14(36.8 \%)(P=0.06)$, due to exacerbation of COPD were also lower in this group. The number of patients who needed antibiotics during the year of follow-up was higher in the IG; 27 (56.3\%), compared to
18 (47.4\%) in the CG, although this was not statistically significant $(P=0.306)$. In contrast, glucocorticoid use was slightly higher in the CG $(44.7 \%)$ than in the IG $(37.5 \%)(P=0.41)$. The length of hospital stay was also shorter in patients who received the SMP-COPD. The main results are detailed in Table 2. On the cumulative survival curve (Figure 2) showing the days from baseline to the first instance of hospital care for exacerbation of COPD, the time to the first event was longer in the IG, although the difference was not significant $(P=0.097)$. There were no differences in mortality, with two deaths $(5.26 \%)$ recorded in the $\mathrm{CG}$ and none in the IG $(P=0.338)$. The number needed to treat (NNT) was calculated using the formula $C I=1-e^{-I R \times t}$, proposed by Suissa, ${ }^{25}$ where $C I$ is cumulative incidence, $I R$ is incidence rate (person-year), and $t$ is time (years). The number of patients with advanced COPD to whom the SMP-COPD would have to be applied for 1 year to prevent the need for one instance of hospital care for exacerbation was 6.25.

\section{Discussion}

Since the 1997 study by Watson et $\mathrm{a}^{26}$ showing the favorable effects of self-management skills in COPD acquired through a written action plan, many authors have conducted clinical trials to evaluate different variables, with conflicting results. Some confirm positive results following the implementation of such programs, although the type of interventions applied varies greatly. ${ }^{27,28}$ Bourbeau et a ${ }^{29}$ found that a self-management program called "Living Well with $\mathrm{COPD}^{\mathbb{}}$ " decreased the use of services and hospitalizations. 
Table 2 Outcome variables at the end of the study

\begin{tabular}{|c|c|c|c|}
\hline Outcome variables & $\begin{array}{l}\text { Control } \\
\mathrm{N}=\mathbf{3 8}\end{array}$ & $\begin{array}{l}\text { Intervention } \\
\mathrm{N}=47\end{array}$ & $P$-value \\
\hline \multicolumn{4}{|l|}{ Secondary outcome variables } \\
\hline No of patients with COPD exacerbations with hospitalization or ER visit & $20(52.6 \%)$ & $19(40.4 \%)$ & 0.262 \\
\hline No of patients with COPD exacerbations ER visit & $14(36.8 \%)$ & $9(19.1 \%)$ & 0.068 \\
\hline No of patients with COPD exacerbations hospitalization & $16(42.1 \%)$ & $12(25.5 \%)$ & 0.106 \\
\hline No of patients who needed antibiotics & 18 (47.4\%) & $27(56.3 \%)$ & 0.306 \\
\hline No of patients who needed glucocorticoids & 17 (44.7\%) & $18(37.5 \%)$ & 0.413 \\
\hline Days of hospital stay due to respiratory cause, mean \pm SD & $12.4 \pm 7.1$ & $9.3 \pm 6.4$ & 0.154 \\
\hline All-cause mortality & $2(5.26 \%)$ & 0 & 0.191 \\
\hline \multicolumn{4}{|l|}{ Primary outcome variables } \\
\hline No COPD exacerbations with hospitalization or A\&E visit & 52 & 42 & \\
\hline Days at risk & 3,801 & 4,700 & \\
\hline Rate of exacerbations with hospitalization or A\&E visit, $n$ (range) & $1.37(1.02-1.79)$ & $0.89(0.64-1.21)$ & 0.049 \\
\hline Rate ratio, n (range) & $1.53(1.01-2.29)$ & & \\
\hline
\end{tabular}

Abbreviation: SD, standard deviation.

However, this benefit has not been confirmed by other authors using similar interventions. ${ }^{27}$ It seems clear that interventions with a single component, such as written action plans or education sessions, do not produce relevant effects. ${ }^{30}$ The evidence suggests that the decisive factor in self-care programs is that they contain several types of components ("multicomponent") and are geared toward improving patients' skills. ${ }^{31}$ As in all the clinical trials published, in our study, it was not possible to blind the investigators to the selfmanagement plan, because of its characteristics. By considering the existing evidence, the SMP-COPD was designed as a multicomponent plan aimed at improving patients' skills in self-care and promoting treatment compliance. However, the high number of patients excluded, similar to that reported by other authors, indicates that these interventions may not be

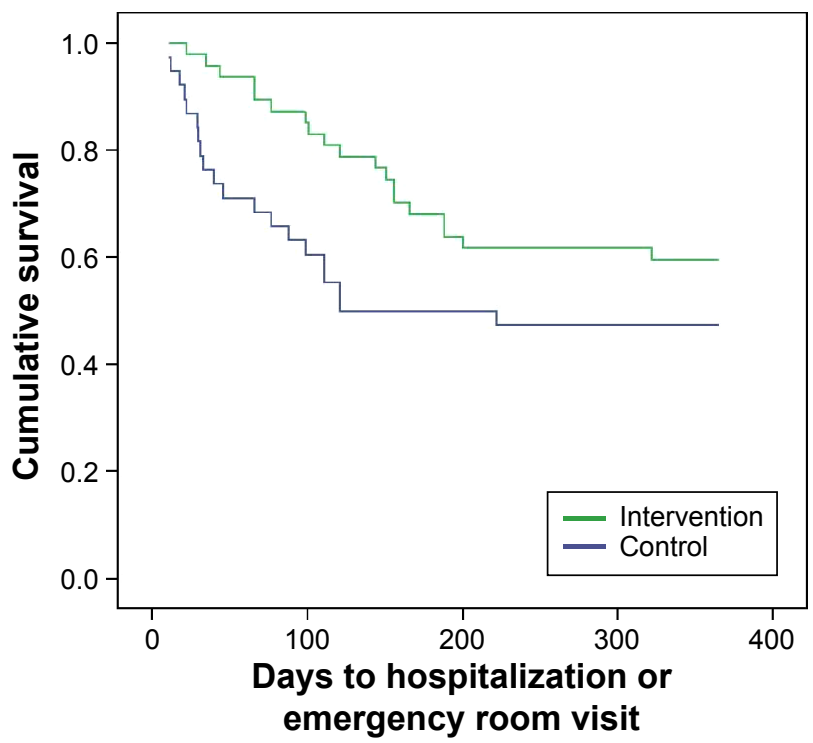

Figure 2 Kaplan-Meier curve.

Notes: Probability of being treated for the first time in hospital during the 12 months of follow-up. $(P=0.097)$. applied systematically to the entire COPD population. ${ }^{32}$ The number of patients with severe disease (more than onehalf had very severe COPD) is higher than that reported in most studies. ${ }^{16}$ In line with the findings of other recent studies, ${ }^{33,34}$ the SMP-COPD led to significant decrease in our primary outcome variable of visits to $A \& E$ and hospitalization due to COPD exacerbation. The number of days of hospitalization for "respiratory cause" was also lower and the time to the first instance of hospital care longer. In terms of the consumption of antibiotics and oral corticosteroids during exacerbations, overall, the IG patients did not use more drugs to treat exacerbations than the CG; antibiotic use by the IG was higher while glucocorticoid use was lower, but the differences were not significant. Some studies found a significant increase in consumption of drugs in the patients subject to self-management interventions, ${ }^{28,33,34}$ but this did not happen in our study. In other studies, the results for these same variables were neither significant nor consistent, ${ }^{35,36}$ but these differences can probably be explained by the heterogeneity in the design of the interventions. The guidelines for action in the case of worsening symptoms differ considerably from one study to another, and are not always clear in the methodology. In our study, the written action plan advised patients to first start on antibiotics and, in a second phase 48 hours later, and only if the symptoms of exacerbation persisted or did not improve, they were to start taking the glucocorticoids. These guidelines may have contributed to the greater use of antibiotics and less use of glucocorticoids in the IG. Patients in the IG were provided with prescriptions at the initial visit, but these were not included in the final analysis of drug consumption. Finally, there may be other confounding variables that influence the consumption of antibiotics and oral glucocorticoids but do not tend to be sufficiently controlled in the majority 
of studies, such as patient initiative and accessibility in terms of seeing primary care doctors. ${ }^{37}$

The NNT over 1 year with the self-management plan of 6.5 that we obtained was similar to the NNT of 8 reported in the most recent Cochrane review in the group of patients at high risk of hospitalization. ${ }^{16}$

\section{Limitations}

Our study has a number of limitations. The sample size is insufficient to reach significance in other variables, such as time to first hospitalization for COPD. Our patients were almost exclusively male (91\%), which probably reflects the demographics of patients currently receiving care in our hospitals. This has also been found in other recent studies, such as Rice et $\mathrm{al}^{34}$ where the percentage of males is even higher, with $97.6 \%$ in the IG and $98.4 \%$ in the CG. We restricted our study to patients with severe or very severe COPD, and do not know whether the same intervention would be effective in patients with milder disease. We also cannot determine the benefits of individual components of the SMPCOPD without conducting trials to directly compare them. Whether or not a more intensive and supervised pulmonary rehabilitation component would add benefit to the management of patients with advanced COPD is an important question that we are unable to answer. Another limitation of the study is the lack of information on the influence of smoking on the results. This, unfortunately, is a factor undervalued in many studies on COPD. Data on smoking were obtained by co-oximetry at the initial visit, but unfortunately, none was obtained at the final visit, so they were not taken into account. The main reason for exclusion (24.8\%) was severe physical deterioration. Within this category, we included patients who could not walk unaided or had lost autonomy for performing activities of daily living (washing and dressing). We know that this exclusion criterion may be controversial, as it is possible that some component of the self-management program could in fact be useful to them, but we considered the physical activity component to be an important part of our program, and that patients with that degree of locomotor disability would not be able to benefit from it, from the group educational session or the exercises contained in the action plan. Although it could be considered a restrictive approach and affect the external validity of the results, there are no reports in the literature of a COPD population with such advanced disease as ours. It is therefore possible that physical deterioration is more prevalent in our population than in other series and this would, in part, explain the high number of patients excluded for this reason. ${ }^{16}$

\section{Implications for practice and research}

One interesting aspect of the study was the fact that the methodological approach was that of a randomized study. Moreover, the interventions were designed rigorously and comprehensively to address the main components of selfmanagement of the disease referred to in other studies, ${ }^{16}$ such as education about the disease; individual training sessions; provision of a written action plan for taking medication in stable periods and when symptoms of exacerbation develop; and for showing how to do physical exercises. Particular attention was also given to ensuring readability and understanding of the material contained in the action plan. The large number of patients included with "advanced" COPD, higher than reported in other series, represents a COPD subgroup with greater needs in terms of care. The fact that a minority of patients may benefit from this intervention should be considered hypothesisgenerating from the point of view of what kind of components need to be applied in different disease phenotypes. ${ }^{32}$

Self-management interventions require the availability of research resources and care tools specifically assigned to the COPD population. Given the magnitude of the global burden of the disease, it seems particularly important to identify which self-management components have more relative effectiveness in terms of health outcomes, since this aspect is considered important for both patients and health care professionals. Studies evaluating the use of health care resources require longer follow-up and need to be adequately powered to detect safety outcomes and improvements in mortality rates. ${ }^{30}$ Because of the complexity of self-management interventions and the general challenges of research in this field, some authors point to the necessity of organizing an international consensus to identify the key components of interventions and establish the end points that should help focus future research. ${ }^{38}$

\section{Conclusion}

To sum up, after applying a self-management program in patients with advanced COPD, there were fewer hospitalizations and $A \& E$ visits for exacerbation of the disease in the group that received the intervention. This type of program can be an effective care tool adapted to the needs of chronic patients. However, further research is required to identify which patients benefit most and which components have the best cost/benefit ratios, and to conduct prospective validations in realistic scenarios.

\section{Acknowledgments}

This study was made possible thanks to support and funding from the following companies: Gas Medi SA, Boehringer Ingelheim, Chiesi, Menarini. The role of these companies was 
limited to financing the project, with no intervention in the development of the material used in the self-management plan or in the writing of the article. Thanks are owed to the following nursing, administration, and IT staff from both the participating hospitals. Without their collaboration, conducting the study would not have been possible. María José Clemente La Serna, Ángela Dólera Martínez, Esperanza Pérez Navarro, Manuela Pérez Maiquez, Concepción Belmonte López, Maria Dolores Cervantes Pérez, Ana Bernal Gilar, Mari Carmen Navarro Leyva, Teresa Abellán Nogueira, Encarnación López López, Juana Maria Muñoz Martínez, Joaquin Moreno Hernandez Ma Patricia Palacio Gaviria, Juan Manuel Moreno Hernández, Pablo Pérez Forca.

\section{Disclosure}

The authors report no conflicts of interest in this work.

\section{References}

1. European Respiratory Society. European Lung White Book. Huddersfield: European Respiratory Society Journals Ltd; 2003.

2. Ferrer M, Alonso J, Morera J, et al. Chronic obstructive pulmonary disease stage and health-related quality of life. Ann Intern Med. 1997;127: 1072-1079.

3. Seemungal TA, Donaldson GC, Paul EA, Bestall JC, Jeffries DJ, Wedzicha JA. Effects of exacerbation on quality of life in patients with chronic obstructive pulmonary disease. Am J Respir Crit Care Med. 1998; 157:1418-1422.

4. Domingo-Salvany A, Lamarca R, Ferrer M, et al. Health-related quality of life and mortality in male patients with chronic obstructive pulmonary disease. Am J Respir Crit Care Med. 2002;166:680-685.

5. Donaldson GC, Seemungal TA, Bhowmik A, Wedzicha JA. Relationship between exacerbation frequency and lung function decline in chronic obstructive pulmonary disease. Thorax. 2002;57:847-852.

6. Ruchlin HS, Dasbach EJ. An economic overview of chronic obstructive pulmonary disease. Pharmacoeconomics. 2001;19:623-642.

7. Casas A, Troosters T, García-Aymerich J, et al. Integrated care prevents hospitalisations for exacerbations in COPD patients. Eur Respir J. 2006; 28:123-130.

8. Wagner EH. Chronic disease management: what will it take to improve care for chronic illness? Eff Clin Pract. 1998;1(1):2-4.

9. Monninkhof E, van der Valk P, van der Palen J, van Herwaarden C, Zielhuis G. Effects of a comprehensive self-management programme in patients with chronic obstructive pulmonary disease. Eur Respir J. 2003; $22: 815-820$

10. Worth H. Self management in COPD: one step beyond? Patient Educ Counsel. 1997;32:S105-S109.

11. Bourbeau J, van der Palen J. Promoting effective self-management programmes to improve COPD. Eur Respir J. 2009;33(3):461-463.

12. Warsi A, Wang PS, LaValley MP, Avorn J, Solomon DH. Self-management education programs in chronic disease: a systematic review and methodological critique of the literature. Arch Intern Med. 2004;164:1641-1649.

13. Ofman JJ, Badamgarav E, Henning JM, et al. Does disease management improve clinical and economic outcomes in patients with chronic diseases? A systematic review. Am J Med. 2004;117:182-192.

14. Turnock AC, Walters EH, Walters JA, Wood-Baker R. Action plans for chronic obstructive pulmonary disease. Cochrane Database Syst Rev. 2005:CD005074.

15. Adams SG, Smith PK, Allan PF, Anzueto A, Pugh JA, Cornell JE. Systematic review of the chronic care model in chronic obstructive pulmonary disease prevention and management. Arch Intern Med. 2007; 167:551-561.
16. Zwerink M, Brusse-Keizer M, van der Valk PD, et al. Self management for patients with chronic obstructive pulmonary disease. Cochrane Database Syst Rev. 2014;3:CD002990.

17. Trappenburg JA, Koevoets L, de Weert-van Oene GH, et al. Action plan to enhance self-management and early detection of exacerbations in COPD patients; a multicenter RCT. BMC Pulm Med. 2009;9:52-62.

18. Board M, Allen SC. A simple drawing test to identify patients who are unlikely to be able to learn to use an inhaler. Int J Clin Pract. 2006;60: 510-513.

19. Mahler DA, Wells CK. Evaluation of clinical methods for rating dyspnea. Chest. 1988;93:580-586.

20. Jones PW, Harding G, Berry P, et al. Development and first validation of the COPD assessment test. Eur Respir J. 2009;34:648-654.

21. Rabe KF, Hurd S, Anzueto A, Barnes PJ, Buist SA, Calverley P. Global strategy for the diagnosis, management and prevention of chronic obstructive pulmonary disease: GOLD executive summary. Am J Respir Crit Care Med. 2007;176:532-555.

22. Charlson M, Szatrowski TP, Peterson J, Gold J. Validation of a combined comorbidity index. J Clin Epidemiol. 1994;47:1245-1251.

23. Miralles R, Sabartés O, Ferrer M, et al. Development and validation of an instrument to predict probability of home discharge from a Geriatric Convalescence Unit in Spain. J Am Geriatr Soc. 2003;51:252-257.

24. Burge S, Wedzicha JA. COPD exacerbations: definitions and classifications. Eur Respir J. 2003;21(Suppl 41):46s-53s.

25. Suissa S. Calculation of number needed to treat. Thorax. 2013;68(6): 540-543.

26. Watson PB, Town GI, Holbrook N, Dwan C, Toop LJ, Drennan CJ. Evaluation of a self-management plan for chronic obstructive pulmonary disease. Eur Respir J. 1997;10(6):1267-1271.

27. Rea H, McAuley S, Stewart A, Lamont C, Roseman P, Didsbury P. A chronic disease management programme can reduce days in hospital for patients with chronic obstructive pulmonary disease. Intern Med $J$. 2004:34(11):608-614.

28. Gallefoss F. The effects of patient education in COPD in a 1-year follow-up randomised, controlled trial. Patient Educ Couns. 2004;52(3): 259-266.

29. Bourbeau J, Julien M, Maltais F, et al. Reduction of hospital utilization in patients with chronic obstructive pulmonary disease: a diseasespecific self-management intervention. Arch Intern Med. 2003;163(5): 585-591.

30. Walters AE, Turnock CA, Walters H, Wood-Baker R. Action plans with limited patient education only for exacerbations of chronic obstructive pulmonary disease. Cochrane Database Syst Rev. 2010:CD005074.

31. Clark MN, Dodge JA, Partridge MR, Martínez FJ. Focusing on outcomes: Making the most of COPD interventions. Int J Chron Obstruct Pulmon Dis. 2009;4:61-77.

32. Bucknall CE, Miller G, Lloyd SM, et al. Glasgow supported selfmanagement trial (GSuST) for patients with moderate to severe COPD: randomized controlled trial. BMJ. 2012;344:e1060.

33. Effing T, Kerstjens H, van der Valk P, Zielhuis G, van der Palen J. (Cost)-effectiveness of self-treatment of exacerbations on the severity of exacerbations in patients with COPD: the COPE II study. Thorax. 2009; 64(11):956-962.

34. Rice KL, Dewan N, Bloomfield HE, et al. Disease management program for chronic obstructive pulmonary disease: a randomized controlled trial. Am J Respir Crit Care Med. 2010;182(7):890-896.

35. Wood-Baker R, McGlone S, Venn A, Walters EH. Written action plans in chronic obstructive pulmonary disease increase appropriate treatment for acute exacerbations. Respirology. 2006;11(5):619-626.

36. Sedeno MF, Nault D, Hamd DH, Bourbeau J. A self-management education program including an action plan for acute COPD exacerbations. COPD. 2009;6(5):352-358.

37. Trappenburg JC, Schaap D, Monninkhof EM, et al. How do COPD patients respond to exacerbations? BMC Pulm Med. 2011;11(43):1-9.

38. Peytremann-Bridevaux I, Staeger P, Bridevaux PO, Ghali WA, Burnand B. Effectiveness of chronic obstructive pulmonary diseasemanagement programs: systematic review and meta-analysis. Am JMed. 2008;121(5):433-443. 
International Journal of COPD

\section{Publish your work in this journal}

The International Journal of COPD is an international, peer-reviewed journal of therapeutics and pharmacology focusing on concise rapid reporting of clinical studies and reviews in COPD. Special focus is given to the pathophysiological processes underlying the disease, intervention programs, patient focused education, and self management protocols.

This journal is indexed on PubMed Central, MedLine and CAS. The manuscript management system is completely online and includes a very quick and fair peer-review system, which is all easy to use. Visit http://www.dovepress.com/testimonials.php to read real quotes from published authors 